\title{
Comparison of clinical and pathological characteristics between screen-detected and self- detected breast cancers: a Hong Kong study
}

\author{
Silvia SS Lau *, Polly SY Cheung, TT Wong, Michael KG Ma, WH Kwan
}

This article was published on 29 Mar 2016 at www.hkmj.org.

\section{A B S T R A C T}

Introduction: Breast cancer is the leading cause of death of Hong Kong women with increasing incidence. This study aimed to determine any prognostic differences between screen-detected and self-detected cases of breast cancer in a cohort of Hong Kong patients.

Methods: This was a case series with internal comparison carried out in a private hospital in Hong Kong. Approximately 3000 cases of Chinese patients diagnosed with ductal carcinoma in situ or invasive breast cancer were reviewed.

Results: The screen-detected group showed better pathological characteristics than the self-detected group. Number of lymph nodes involved, invasive tumour size, and tumour grade were more favourable in the screen-detected group. There was also a lower proportion of patients with pure invasive ductal carcinoma and mastectomy in the screen-detected group.
Conclusion: This study provides indirect evidence that women in the local population may gain clinical benefit from regular breast cancer screening. The findings need to be validated in a representative population of Hong Kong women.

Hong Kong Med J 2016;22:202-9

DOI: $10.12809 / \mathrm{hkmj} 154575$

${ }^{1}$ SSS Lau *, MPH (HK), MSc

2 PSY Cheung, FCSHK, FHKAM (Surgery)

2 TT Wong, FCSHK, FHKAM (Surgery)

${ }^{2}$ MKG Ma, FRCS (Eng), FHKAM (Surgery)

${ }^{3}$ WH Kwan, FHKCR, FHKAM (Radiology)

${ }^{1}$ Medical Physics \& Research Department

2 Breast Care Centre

${ }^{3}$ Department of Radiotherapy

Hong Kong Sanatorium \& Hospital, Happy Valley, Hong Kong

* Corresponding author: silvialauss@yahoo.com.hk

New knowledge added by this study

- It is possible that in the Hong Kong local population, breast cancer detected by screening mammogram or ultrasound has more favourable pathological characteristics than self-detected tumours.

Implications for clinical practice or policy

- Further large-scale clinical trials to evaluate the cost-effectiveness and clinical efficacy of breast cancer screening in the Hong Kong local population should be conducted. Change in prevalence of breast cancer in the female population of Hong Kong and advances in breast imaging technology may have altered the cost-benefit ratio of breast cancer screening.

\section{Introduction}

Breast cancer is the second leading cause of death due to cancer in the world with an age-standardised incidence rate of 43.1 per 100000 population in 2012. ${ }^{1}$ Gøtzsche and Nielsen ${ }^{2}$ showed that early detection of breast cancer can reduce mortality. The benefit of mammographic screening in terms of lives saved is greater than the harm caused by overdiagnosis; according to Duffy et al, 2 to 2.5 lives are saved for every overdiagnosed case.

Breast cancer is also a significant health problem in Hong Kong. It is the third leading cause of death due to cancer and the most common cancer of women. ${ }^{4}$ The crude incidence rate of breast cancer in Hong Kong increased from 57 per 100000 in 2000 to 91.7 per 100000 in $2012 .{ }^{4}$
Despite this, Hong Kong does not have a universal breast cancer screening programme for the whole population. Women who wish to be screened must arrange and pay for it. As the incidence of breast cancer in Hong Kong is low compared with western populations, there is concern about the costeffectiveness of a universal screening programme. The incremental cost-effectiveness ratio for mammography examination is relatively higher than in the United States. ${ }^{5}$

In view of the controversy there is a need for further studies in Hong Kong to provide local data on the efficacy of breast cancer screening by mammogram. This will enable policy makers, doctors, and patients to decide on the most costeffective method of early breast cancer detection. 
This study aimed to investigate whether there are any prognostic differences between screendetected (mammography, ultrasound examination of breasts, or clinical examination) and self-detected breast cancers in a cohort of Hong Kong breast cancer patients and to determine whether there is any benefit of detection by screening.

\section{Methods}

\section{Background of database used}

A retrospective study was conducted at the Hong Kong Sanatorium \& Hospital (HKSH), a private hospital in Hong Kong where the Breast Care Centre provides a comprehensive breast screening programme and breast cancer consultation services for patients. Since 2003, all breast cancer cases in the hospital have been discussed at a weekly multidisciplinary breast conference. Over 50\% of cases are referred from public hospitals spread across the whole territory.

Clinical history, and information about diagnosis, neoadjuvant chemotherapy, surgical treatment, postoperative pathology, and treatment recommendations for each patient are recorded in a structured datasheet before the conference. The Chairman of the conference validates data by checking the data logic during case presentation and, if necessary, clarifying details with the doctorin-charge. A research assistant again checked data validity and logic by computer for cases selected for analysis. Frequency tables, scatter plots, and crosstabulation tables were generated for each required variable to ensure completeness and to determine whether any data deviated from usual clinical practice.

\section{Subjects}

All Chinese females confirmed to have in-situ or invasive breast cancer from or referred to $\mathrm{HKSH}$ between 2003 and 2010 were included in this study. For analysis of trends of prognostic factors, only patients between 2004 and 2010 were included as the sample size for year 2003 was small after dividing data into subsets by year and prognostic factors.

\section{Ethics}

The use of the database for data analysis for health care research purposes was approved by the Research Ethics Committee of HKSH.

\section{Epidemiological analysis}

Patients were classified into two groups, screendetected or self-detected tumour, before the outcomes were reviewed. The screen-detected group included screening mammogram, screening ultrasonogram, or clinical examination. The self-

\section{研究香港從乳癌篩檢中或乳房自我檢查中得悉患 癌的病人臨床和病理特徵比較 \\ 劉淑思、張淑儀、黃亭亭、馬健基、關永康}

引言：香港女性的乳癌發病率呈上升趨勢, 並已成為本地女性引致死 亡的主要原因。本研究旨在探討從篩檢中或自我檢查中得悉患有乳癌 的香港患者的預後差異。

方法：這病例系列的內部比較於香港一家私家醫院內進行, 共回顧約 3000 個確診為乳腺導管原位癌或浸潤性乳腺癌患者的紀錄。

結果：從篩檢中得悉患有乳癌的患者比乳房自我檢查的組別有較佳的 病理特徵, 她們所涉及的淋巴結、侵襲性腫瘤大小和腫瘤級別都對預 後較有利, 而且患有純浸潤性導管癌和乳房切除術的比率亦較低。

結論：本研究間接證明了為本地女性進行常規乳癌篩查的臨床效益, 但研究結果須進一步在香港具代表性的婦女人口中進行驗證。

detected group included self-examination or presence of symptoms at presentation. Such information was recorded on the datasheet that was anonymised. Demographic data of patients were retrieved and significant prognostic factors according to St Gallen's risk categorisation were analysed.

\section{Data analysis}

The Statistical Package for the Social Sciences (Windows version 18.0; SPSS Inc, Chicago [IL], US) was used for analysis. Descriptive statistics were used to summarise demographics, as well as pathological and clinical characteristics of patients. Univariate logistic regression was used to determine odds ratio (OR) of screening status for different pathological characteristics. Association between type of surgery and screening status, tumour size, and age was determined by univariate logistic regression. In order to know how effective the models were in predicting the type of surgery, Hosmer-Lemeshow goodness-of-fit test was used, in which the null hypothesis was no significant difference between observed and predicted values of dependent variable. Multivariate analysis was performed on the type of surgery, which was dichotomous having breastconserving surgery (BCS) as reference group with adjustment of confounding factors that included detection mode, lymph node status, tumour size, tumour grade, tumour stage, oestrogen receptors (ER), progesterone receptors (PR), HER2 score, and age. Nagelkerke's $\mathrm{R}^{2}$ was used to show explanatory power of model.

Data for invasive tumour size were plotted against screening status to gain an overview of changes between 2004 and 2010. 


\section{Results}

Data from 2763 Chinese women out of 3373 cases confirmed to have in-situ or invasive breast cancer between 2003 and 2010 were analysed. Of the 610 cases excluded from analysis, 210 were due to unknown histology, 258 with unknown report type, and 142 with unknown first-detection method. Of the patients included, $75.7 \%$ were in the self-detected group and $24.3 \%$ in the screen-detected group. The mean age of patients was 50.2 (range, 24-92) years, with the highest number in both groups aged 40 to 49 years (Table 1). There was also a significant proportion of younger patients $(<40$ years) in the self-detected group (16.6\%). The screen-detected group had a statistically significant higher age at first live birth, although the difference in mean age was only 1 year.

Pathological characteristics of self-detected and screen-detected groups are shown in Table 1. There was a significant difference in ER, but no demonstrable significant difference in PR or HER2 status. Approximately $4 \%$ of patients in both groups did not undergo surgery for a variety of reasons, thus only limited information was available from biopsy specimens about pathological characteristics.

The odds of having 0 lymph nodes, smaller tumour size, or ER/PR positivity were all higher in the screen-detected group. Results were not statistically significant for HER2 positivity although it showed higher odds in the self-detected group (Table 2).

Table 3 shows that after adjustment for potential confounding factors, patients with screen-detected cancers were less likely to require mastectomy $(\mathrm{OR}=0.658, \mathrm{P}=0.004)$. Statistically significant factors associated with a higher risk of mastectomy included: positive lymph node, tumour grading higher than 1 , tumour size of $>2 \mathrm{~cm}$, older age, and positive HER2 score. The Hosmer-Lemeshow test had a P value of 0.88 , meaning the goodness of fit of the model was satisfactory at the $5 \%$ significance level.

The Figure shows the trend in differences between groups for invasive tumour size between 2004 and 2010. In the screen-detected group, there was an increasing proportion of invasive tumours detected when $\leq 2 \mathrm{~cm}$ and a decreasing trend for detection of tumour of $>2$ to $5 \mathrm{~cm}$. There was, however, no significant difference between groups for trend of histology, lymph node involvement, tumour grade, type of surgery, ER positivity, or HER2 positivity.

\section{Discussion}

Although the incidence of breast cancer in Hong Kong is half that of the United Kingdom, the screen-detected group showed a pattern of breast cancer diagnosis at an earlier stage compared with the self-detected group. This is consistent with the findings of similar studies in other countries, such as Singapore. ${ }^{6}$ This study may provide evidence that supports the benefits of regular screening to detect breast cancer lesions at an early stage in Hong Kong women. This will facilitate less invasive surgery and a possibly better overall clinical outcome. Breast cancer screening programmes have been established in many countries around the world. In order to bring Hong Kong in line with world health care standards, more research that will result in established and unified guidelines for the local population is required.

\section{Pathological risk factors}

Significant prognostic factors in the St Gallen's risk categorisation, including number of lymph nodes with disease, size of primary tumour, and histological grade between the self-detected and screen-detected groups were analysed. These prognostic factors were chosen because they have been verified as significant in the local population. ${ }^{7}$

In this study, screen-detected breast tumours were of smaller size, at a lower stage and grade, and with less lymph node involvement. Screen-detected breast cancers in the Hong Kong population may thus carry a better prognosis than self-detected ones. This can serve as evidence that fulfils most of the Wilson and Jungner criteria for a screening evaluation programme ${ }^{8}$ and also supports breast cancer screening in Hong Kong. Some of the criteria for breast cancer screening that have been fulfilled include: an important health problem (it is the second leading cause of death from cancer in Hong Kong), acceptable treatment is well established, facilities for diagnosis and treatment are widely available, natural history of the disease is well understood, and effective treatment is available for early-stage disease. Findings of this study suggested that breast tumours detected on screening have a better prognosis. The cost-benefit balance was not addressed, however, nor screening/case-finding policies.

In the screen-detected group, a higher percentage of tumours were ER positive. It was revealed that ER and PR are significant prognostic factors within the first 10 years following diagnosis. ${ }^{9}$ It is known that HER2 positivity shows poorer prognosis $^{8}$ but there was no significant difference in HER2 status between screen-detected and selfdetected groups.

\section{Trends}

By observing the trend in size of invasive tumour at first presentation, the stable pattern in the selfdetected group suggests that tumour detection by the general population has not improved. On the contrary, an increasing detection of tumours of $\leq 2 \mathrm{~cm}$ in the screen-detected group is an evidence of the improved efficacy of screening using new 
TABLE I. Comparison of patient characteristics between self-detected and screen-detected groups by Chi squared test

\begin{tabular}{|c|c|c|c|}
\hline & Self-detected $(n=2092)$ & Screen-detected $(n=671)$ & $P$ value \\
\hline \multicolumn{4}{|l|}{ Age (years) } \\
\hline Mean (range) & $50.2(24-92)$ & $51.1(26-90)$ & $<0.001$ \\
\hline $20-29$ & $19(0.9 \%)$ & $1(0.1 \%)$ & \\
\hline $30-39$ & $329(15.7 \%)$ & $46(6.9 \%)$ & \\
\hline $40-49$ & $808(38.6 \%)$ & $292(43.5 \%)$ & \\
\hline $50-59$ & $546(26.1 \%)$ & $220(32.8 \%)$ & \\
\hline $60-69$ & $217(10.4 \%)$ & $78(11.6 \%)$ & \\
\hline $70-79$ & $123(5.9 \%)$ & $22(3.3 \%)$ & \\
\hline$\geq 80$ & $47(2.2 \%)$ & $10(1.5 \%)$ & \\
\hline Unknown & $3(0.1 \%)$ & $2(0.3 \%)$ & \\
\hline Mean (range) age at menarche (years) & $13.0(9-55)$ & $13.2(9-30)$ & 0.11 \\
\hline Mean (range) age at first live birth (years) & $27.7(16-50)$ & $28.8(16-45)$ & $<0.001$ \\
\hline Mean (range) age at menopause (years) & $49.6(26-60)$ & $50.0(34-59)$ & 0.28 \\
\hline LN status & & & $<0.001$ \\
\hline 0 & $859(41.1 \%)$ & $321(47.8 \%)$ & \\
\hline $1-3$ & $529(25.3 \%)$ & $71(10.6 \%)$ & \\
\hline $4-9$ & $155(7.4 \%)$ & $20(3.0 \%)$ & \\
\hline$>9$ & $82(3.9 \%)$ & $7(1.0 \%)$ & \\
\hline Unknown & $467(22.3 \%)$ & $252(37.6 \%)$ & \\
\hline Invasive tumour size $(\mathrm{cm})$ & & & $<0.001$ \\
\hline$\leq 2$ & $956(45.7 \%)$ & 339 (50.5\%) & \\
\hline$>2-5$ & $794(38.0 \%)$ & $96(14.3 \%)$ & \\
\hline$>5$ & $86(4.1 \%)$ & $3(0.4 \%)$ & \\
\hline Unknown & $256(12.2 \%)$ & $233(34.7 \%)$ & \\
\hline Tumour grade & & & $<0.001$ \\
\hline 1 & $240(11.5 \%)$ & $113(16.8 \%)$ & \\
\hline 2 & $667(31.9 \%)$ & $196(29.2 \%)$ & \\
\hline 3 & $926(44.3 \%)$ & $127(18.9 \%)$ & \\
\hline Unknown & $259(12.4 \%)$ & $235(35.0 \%)$ & \\
\hline Tumour stage & & & $<0.001$ \\
\hline 0 & $226(10.8 \%)$ & $214(31.9 \%)$ & \\
\hline 1 & $698(33.4 \%)$ & $300(44.7 \%)$ & \\
\hline 2 & $902(43.1 \%)$ & $131(19.5 \%)$ & \\
\hline 3 & $250(12.0 \%)$ & $26(3.9 \%)$ & \\
\hline 4 & $16(0.8 \%)$ & $0(0.0 \%)$ & \\
\hline \multicolumn{4}{|l|}{ Type of surgery } \\
\hline Nil & $73(3.5 \%)$ & $27(4.0 \%)$ & $<0.001$ \\
\hline BCS & $925(44.2 \%)$ & $388(57.8 \%)$ & \\
\hline Mastectomy & $1094(52.3 \%)$ & $256(38.2 \%)$ & \\
\hline \multicolumn{4}{|l|}{ ER } \\
\hline Negative & $519(24.8 \%)$ & $120(17.9 \%)$ & $<0.001$ \\
\hline Positive & $1551(74.1 \%)$ & $543(80.9 \%)$ & \\
\hline Unknown & $22(1.1 \%)$ & $8(1.2 \%)$ & \\
\hline \multicolumn{4}{|l|}{ PR } \\
\hline Negative & $783(37.4 \%)$ & $224(33.4 \%)$ & 0.06 \\
\hline Positive & $1286(61.5 \%)$ & $439(65.4 \%)$ & \\
\hline Unknown & $23(1.1 \%)$ & $8(1.2 \%)$ & \\
\hline \multicolumn{4}{|l|}{ HER2 score } \\
\hline Negative & $1512(72.3 \%)$ & 492 (73.3\%) & 0.35 \\
\hline Positive & 509 (24.3\%) & $150(22.4 \%)$ & \\
\hline Unknown & 71 (3.4\%) & $29(4.3 \%)$ & \\
\hline
\end{tabular}

Abbreviations: BCS = breast-conserving surgery; ER = oestrogen receptor; HER2 = human epidermal growth factor receptor 2; LN = lymph node; $P R=$ progesterone receptor 
TABLE 2. Univariate analysis by logistic regression for all cases

\begin{tabular}{|c|c|c|c|}
\hline & OR by self-detected & 95\% Confidence interval & $P$ value \\
\hline \multicolumn{4}{|l|}{ LN } \\
\hline \multicolumn{4}{|l|}{0} \\
\hline $1-3$ & 2.784 & $2.107-3.680$ & $<0.001$ \\
\hline $4-9$ & 2.896 & $1.787-4.694$ & $<0.001$ \\
\hline$>9$ & 4.378 & $2.002-9.572$ & $<0.001$ \\
\hline \multicolumn{4}{|l|}{ Tumour size $(\mathrm{cm})$} \\
\hline \multicolumn{4}{|l|}{$\leq 2$} \\
\hline$>2-5$ & 2.933 & $2.295-3.748$ & $<0.001$ \\
\hline$>5$ & 10.165 & 3.194-32.355 & $<0.001$ \\
\hline \multicolumn{4}{|l|}{ Grade } \\
\hline \multicolumn{4}{|l|}{1} \\
\hline 2 & 1.602 & $1.218-2.108$ & 0.001 \\
\hline 3 & 3.433 & $2.567-4.590$ & $<0.001$ \\
\hline \multicolumn{4}{|l|}{ Stage } \\
\hline \multicolumn{4}{|l|}{0} \\
\hline 1 & 2.203 & $1.749-2.775$ & $<0.001$ \\
\hline 2 & 6.520 & $5.018-8.471$ & $<0.001$ \\
\hline 3 & 9.105 & $5.834-14.209$ & $<0.001$ \\
\hline 4 & $1.53 \mathrm{e} 9$ & 0.000 & $>0.99$ \\
\hline \multicolumn{4}{|l|}{ Surgery } \\
\hline \multicolumn{4}{|l|}{ BCS } \\
\hline Mastectomy & 1.793 & $1.497-2.147$ & $<0.001$ \\
\hline \multicolumn{4}{|l|}{ ER } \\
\hline \multicolumn{4}{|l|}{ Negative } \\
\hline Positive & 0.660 & $0.529-0.824$ & $<0.001$ \\
\hline \multicolumn{4}{|l|}{ PR } \\
\hline \multicolumn{4}{|l|}{ Negative } \\
\hline Positive & 0.838 & $0.697-1.007$ & 0.06 \\
\hline \multicolumn{4}{|l|}{ HER2 score } \\
\hline \multicolumn{4}{|l|}{ Negative } \\
\hline Positive & 1.104 & $0.896-1.360$ & 0.35 \\
\hline
\end{tabular}

Abbreviations: $\mathrm{BCS}=$ breast-conserving surgery; $\mathrm{ER}$ = oestrogen receptor; $\mathrm{HER} 2=$ human epidermal growth factor receptor $2 ; \mathrm{LN}=$ lymph node; $\mathrm{OR}=$ odds ratio; $\mathrm{PR}=$ progesterone receptor of ER/PR and HER2 are intrinsic characteristics of tumours. They should not differ whether or not a tumour is detected at an earlier stage. Therefore no statistically significant difference in these intrinsic characteristics was expected between screendetected and self-detected tumours. Nonetheless, in this study, tumours in the screen-detected group were more likely to be positive for ER, and this may carry some prognostic implication. Further studies may be required to investigate whether tumours detected at an earlier stage show differences in intrinsic factors.

\section{Surgical treatment}

When choosing between BCS and mastectomy, detection mode, number of positive lymph nodes, invasive tumour size, grading, staging, ER, PR, HER2 score, and age were potential significant factors. With adjustment of these factors, detection mode may be an independent factor that affects choice of surgery. Screen-detected patients tended to have BCS when the effect of number of positive lymph nodes, tumour size, grading, HER2 score, and age was excluded. Such surgery is less invasive than mastectomy and is associated with better cosmetic outcome, and may have an important impact on the psychological health and coping ability of patients recovering from breast cancer. Breast cancer screening may lead to less invasive treatment with better rehabilitation outcome.

\section{Potential biases}

Many studies have claimed longer survival in patients with breast cancer detected by screening mammogram. Nonetheless, this may be due to leadtime bias: survival time appears longer because diagnosis is earlier than in patients where tumour has been self-detected or become symptomatic. In addition, there is selection bias since women with a family history of breast cancer or who are better informed are more likely to submit to breast cancer screening.

\section{Cost-effectiveness}

A local study suggested that population-based breast technology such as mammogram or sonogram. There remains room for improvement in the application of radiology. Apart from magnetic resonance imaging, digital mammography may be more efficacious in women younger than 50 years. ${ }^{9}$ This may change future trends in early diagnosis.

\section{Hormonal receptor and HER2 status}

Unlike tumour size and number of lymph nodes involved, both of which are increased in breast tumours detected at a later stage with a consequent poorer prognosis, prognostic factors such as status cancer screening by mammography may not be cost-effective in Hong Kong women. ${ }^{5}$ This balance between cost and benefit may be altered by the rising incidence of breast cancer in Hong Kong and the availability of advanced breast imaging technology that is associated with fewer false-positive diagnoses. There may also be a broader range of screening options, hence cost will be lowered. Therefore, the incremental cost-effectiveness ratio may be lowered.

\section{Recommendations}

A prospective randomised controlled trial would 
TABLE 3. Logistic regression for type of surgery (breast-conserving surgery vs mastectomy)

\begin{tabular}{|c|c|c|c|c|}
\hline & \multicolumn{2}{|c|}{ Univariate analysis } & \multicolumn{2}{|c|}{ Multivariate analysis* } \\
\hline & OR $(95 \% \mathrm{Cl})$ & $P$ value & OR (95\% Cl) & $P$ value \\
\hline LN & & $<0.001$ & & $<0.001$ \\
\hline \multicolumn{5}{|l|}{0} \\
\hline $1-3$ & $1.937(1.581-2.374)$ & & $1.892(1.501-2.384)$ & \\
\hline $4-9$ & $7.316(4.706-11.375)$ & & $7.156(4.424-11.575)$ & \\
\hline$>9$ & $5.634(3.23-9.827)$ & & $5.723(2.89-11.334)$ & \\
\hline Tumour size $(\mathrm{cm})$ & & $<0.001$ & & $<0.001$ \\
\hline \multicolumn{5}{|l|}{$\leq 2$} \\
\hline$>2-5$ & $1.679(1.409-2.0)$ & & $1.184(0.949-1.478)$ & \\
\hline$>5$ & 11.905 (5.697-24.874) & & $5.448(2.396-12.385)$ & \\
\hline Grade & & $<0.001$ & & 0.02 \\
\hline \multicolumn{5}{|l|}{1} \\
\hline 2 & $2.118(1.636-2.742)$ & & $1.58(1.147-2.176)$ & \\
\hline 3 & $2.177(1.692-2.80)$ & & $1.398(1.01-1.936)$ & \\
\hline Stage & & $<0.001$ & & \\
\hline \multicolumn{5}{|l|}{0} \\
\hline 1 & $0.809(0.64-1.02)$ & & & \\
\hline 2 & $1.443(1.147-1.817)$ & & & \\
\hline 3 & $6.513(4.429-9.576)$ & & & \\
\hline 4 & $17.070(2.224-131.006)$ & & & \\
\hline Mode of detection & & $<0.001$ & & 0.004 \\
\hline \multicolumn{5}{|l|}{ Self-detected } \\
\hline Screen-detected & $0.558(0.466-0.668)$ & & $0.658(0.497-0.872)$ & \\
\hline ER & & 0.028 & & \\
\hline \multicolumn{5}{|l|}{ Negative } \\
\hline Positive & $0.817(0.681-0.979)$ & & & \\
\hline PR & & $<0.001$ & & \\
\hline \multicolumn{5}{|l|}{ Negative } \\
\hline Positive & $0.731(0.624-0.858)$ & & & \\
\hline HER2 score & & $<0.001$ & & $<0.001$ \\
\hline \multicolumn{5}{|l|}{ Negative } \\
\hline Positive & $1.560(1.301-1.871)$ & & $1.604(1.243-2.07)$ & \\
\hline Age & 1.035 (1.027-1.042) & $<0.001$ & 1.039 (1.029-1.049) & $<0.001$ \\
\hline
\end{tabular}

Abbreviations: $\mathrm{Cl}=$ confidence interval; $\mathrm{ER}=$ oestrogen receptor; HER2 = human epidermal growth factor receptor 2 ; $\mathrm{LN}=$ lymph node; $\mathrm{OR}=$ odds ratio; $\mathrm{PR}=$ progesterone receptor

* Hosmer-Lemeshow test: Chi squared statistics: 3.692 ( $P=0.884)$; Nagelkerke's $R^{2}=0.206$

be the most effective study design to evaluate the effectiveness of mammogram screening. This would require a huge amount of resources, however. In addition, education level and household income, which are risk factors for breast cancer, may affect a woman's decision to undergo a mammogram. These confounding factors should be considered when determining the effect of mammogram examination on development of breast cancer. Postmenopausal hormone replacement therapy also affects the density of breast tissue that may hinder the effectiveness of mammography for breast cancer screening. ${ }^{10}$

The lack of a population-based breast cancer screening programme in Hong Kong should prompt study of the attitude of Hong Kong women towards breast cancer screening. Quantitative surveys or qualitative interviews such as focus groups could help determine their opinion of mammogram screening, what proportion of women perform regular selfexamination or undergo clinical breast examinations 


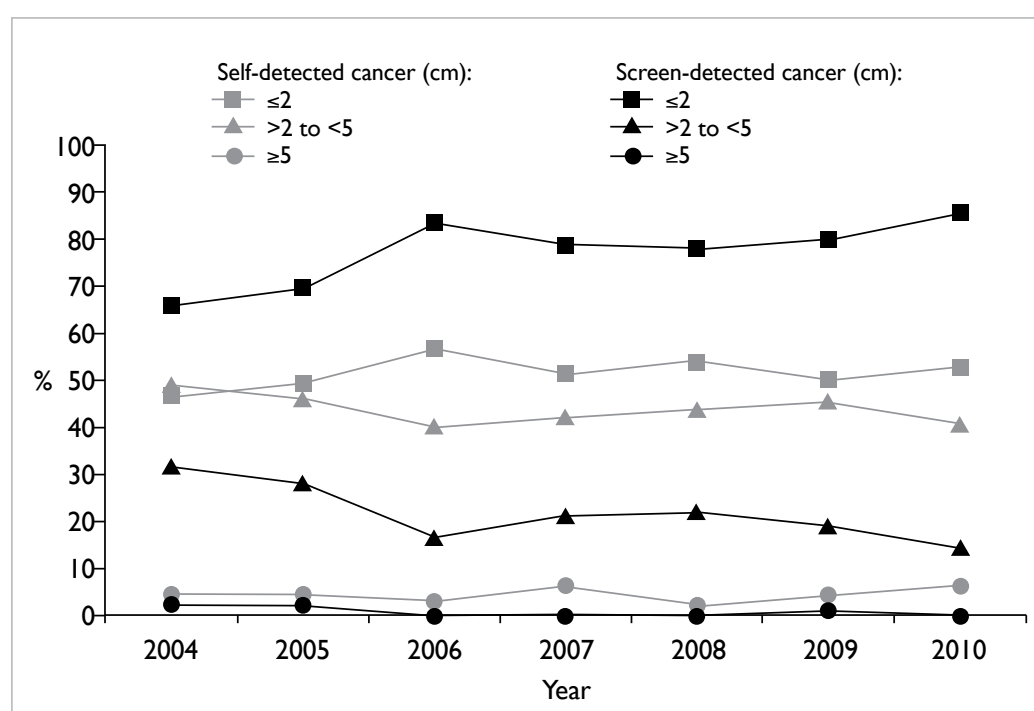

FIG. Trend of invasive tumour size of screen-detected and self-detected groups

and regular mammogram examinations and how often, and whether age is a contributing factor. Trend study may also be meaningful if a particular age-group shows an increasing or decreasing trend for any of the examinations. Understanding level of knowledge about risk factors for breast cancer can also guide appropriate education about breast cancer prevention.

\section{Limitations of this study}

The major strength of this study is the large number of cases in the database, which is one of the most comprehensive breast cancer databases available in Hong Kong in terms of surgical and pathological characteristics. This provides valuable information about the characteristics of breast cancers detected by oneself and through screening, thus allowing a better understanding of the potential benefits of screening by mammogram or ultrasound examination.

This study has limitations. First, it was not a randomised controlled trial. The presence of confounding factors such as living standard, household income, and education level could not be totally excluded. There were also more self-detected than screen-detected patients in this study, thus data might skew towards self-detected cases. It is ethically difficult to randomise women to a control group of education and regular breast self-examination, or an intervention group of regular breast cancer screening by imaging.

Second, data were derived from a single private hospital and findings may not be representative of the Hong Kong population in general. Self-selection bias, especially for attending a private hospital, is also possible. Nonetheless, this is probably one of the largest breast cancer databases in Hong Kong, thus one of the best available sources of information options at present.

Third, secondary data that had been used in this study may not be in a format that met the research question. Some information required may not be available from secondary data. Only 2198 (79.6\%) patients were included in the multivariate logistic regression. Other medical and non-medical factors that could have affected the choice of surgery in individual patients might be related to the practice of screening. Data on parity of women and breastfeeding experience, which may be of interest/ relevance, were also not available. Also, the potential benefits and harm of screening were not thoroughly examined due to the unavailability of data for survival, mortality, and side-effects. For this study, a long period of time was required to examine the data and filter out required variables for analyses as there were more than 200 variables in the database. Information bias also exists as complete blinding of the analysts was not possible.

\section{Conclusion}

This study suggests that in the local Hong Kong population, breast cancers detected by screening mammogram or ultrasound tend to be of smaller size, lower stage, lower grade and with less lymph node involvement, and consequent better prognosis. Although this may not be considered conclusive evidence to support regular screening imaging of Hong Kong women on a population-wide basis, it provides indirect evidence that women in our local population may gain clinical benefit from such a programme.

\section{Acknowledgements}

This article is adapted from a dissertation submitted in partial fulfilment of the requirements for the Master of Public Health at the University of Hong Kong, Hong Kong Special Administrative Region, China. The dissertation was awarded distinction in 2012. Part of the material in this article was presented in the Hong Kong Sanatorium \& Hospital Li Shu Pui Symposium 2012 in Hong Kong.

The first author would like to acknowledge Dr Joseph Wu, Assistant Professor, School of Public Health, Li Ka Shing Faculty of Medicine, The University of Hong Kong, for his supervision of the project leading to completion of the dissertation for the Master of Public Health course. The authors would also like to thank $\mathrm{Dr}$ Andrew Ho, Senior Research Assistant, who is statistical advisor of the project. Finally, the authors would like to express sincere appreciation to staff of Information Technology Department of Hong Kong Sanatorium \& Hospital, who helped retrieve all necessary data for the study. 


\section{Declaration}

All authors have disclosed no conflicts of interest.

\section{References}

1. GLOBOCAN 2012: Estimated cancer incidence, mortality and prevalence worldwide in 2012. Available from: http:// globocan.iarc.fr/Pages/fact_sheets_population.aspx. Accessed Dec 2015.

2. Gøtzsche PC, Nielsen M. Screening for breast cancer with mammography. Cochrane Database Syst Rev 2011;(1):CD001877.

3. Duffy SW, Tabar L, Olsen AH, et al. Absolute numbers of lives saved and overdiagnosis in breast cancer screening, from a randomized trial and from the Breast Screening Programme in England. J Med Screen 2010;17:25-30.

4. Hong Kong Cancer Registry. Female breast cancer in Hong Kong. Available from: http://www3.ha.org.hk/cancereg/ breast_2012.pdf. Accessed Jan 2016.

5. Wong IO, Kuntz KM, Cowling BJ, Lam CL, Leung GM. Cost-effectiveness analysis of mammography screening in Hong Kong Chinese using state-transition Markov modelling. Hong Kong Med J 2010;16(Suppl 3):38S-41S.

6. Chuwa EW, Yeo AW, Koong HN, et al. Early detection of breast cancer through population-based mammographic screening in Asian women: a comparison study between screen-detected and symptomatic breast cancers. Breast J 2009;15:133-9.

7. Yau TK, Soong IS, Chan K, et al. Evaluation of the prognostic value of 2005 St. Gallen risk categories for operated breast cancers in Hong Kong. Breast 2008;17:5863.

8. Wilson JM, Jungner G. Principles and practice of screening for disease. Public Health Papers. No. 34. Geneva: World Health Organization; 1968.

9. Soerjomataram I, Louwman MW, Ribot JG, Roukema JA, Coebergh JW. An overview of prognostic factors for longterm survivors of breast cancer. Breast Cancer Res Treat 2008;107:309-30

10. Cox B, Ballard-Barbash R, Broeders M, et al. Recording of hormone therapy and breast density in breast screening programs: summary and recommendations of the International Cancer Screening Network. Breast Cancer Res Treat 2010;124:793-800. 